\title{
DEVELOPMENT OF A ROAD TRAFFIC NOISE PREDICTION MODEL UNDER UNINTERRUPTED TRAFFIC FLOW CONDITIONS
}

\author{
H.N. RAJAKUMARA ${ }^{1} \&$ R.M. MAHALINGE GOWDA ${ }^{2}$ \\ ${ }^{1}$ Department of Civil Engineering, Adhiyamaan College of Engineering, Hosur, Tamil Nadu, India. \\ ${ }^{2}$ Department of Civil Engineering, P.E.S. College of Engineering, Mandya, Karnataka, India.
}

\begin{abstract}
The main objective of this study is to develop a noise prediction model under uninterrupted traffic flow conditions. In this study, Bangalore city in Karnataka, India, was selected as the study area. The study locations are so chosen as to represent the different zones within an urban area like residential zone, commercial zone, silent zone and heavy traffic zone. Traffic noise was measured using the $L_{\mathrm{eq}}$ index with an A-weighted scale of decibel unit for a 1-hour period at each study location. Based on field observed traffic data, a multiple regression noise prediction model was developed by considering all major causative factors. In the process of model development, a mean standard error of $2.32 \mathrm{~dB}(\mathrm{~A})$ with $r^{2}$ value of 0.82 was observed. The validation of the model was done by collecting traffic data from Mysore city in Karnataka, India. The results of the model validation indicated that the model is accurate to $2.6 \mathrm{~dB}(\mathrm{~A})$ with $r^{2}$ value of 0.78 . Statistical analysis was also done using the paired $t$-test technique on predicted and observed noise levels. The results indicated that the $t$-statistical value of the model is less than the $t$-critical value. This means that the values predicted by the model fit significantly with the field observed ones and that the independent variables used in the model provide a better explanation of the dependent variable $\left(L_{\text {eq }}\right)$. The model developed in this study was also compared with the Federal Highway Administration (FHWA) Traffic Noise Model from USA and the prediction results indicated that the values obtained from the present model are in good agreement with the field observed values than the FHWA model. Therefore, the present model can be used for managing urban road traffic noise in the Indian context.

Keywords: acoustic equivalence, distance, ground absorption, noise barriers, road gradient, road traffic noise, traffic speed, traffic volume, uninterrupted traffic flow.
\end{abstract}

\section{INTRODUCTION}

The transportation system has contributed significantly to the development of human civilization. The largest share of transport activity is by road [1]. Over the last 40 years, there has been a ten-fold increase in the number of motorized vehicles. In future if the same trend continues, there will be a substantial increase in the number of vehicles, leading to enormous increase in the traffic noise levels in the road side environment [2]. Traffic flow will increase because of the expected demographic explosion, slower rate of road mileage growth and faster rate of vehicles growth in the market. Consequently, the increased traffic flows will use a large proportion of the road network with the attendant noise levels becoming higher [3]. Based on recent trends, it is possible to conclude with reasonable certainty that the noise will increase in the future and that more people will be exposed to the disturbing noise [4]. People residing near roadways will consequently be exposed to the increased noise due to increase in the density of traffic. The construction of multi-lane motorways at a rapid rate in developed countries and even in many developing nations during the last few decades has allowed large volumes of traffic to travel at a sustained speed. Another important source of noise on the roads is the speed of traffic. As a general rule, the faster the vehicles move, the greater is the volume of noise generated [5]. Surveys conducted in many countries have shown that traffic noise is one of the principal environmental nuisances in urban areas [6].

In a rapidly urbanizing country like India, the transportation sector is growing quickly and the number of vehicles on Indian roads is increasing at a rate more than $7 \%$ per annum [1]. The 
environmental quality of Indian cities is gradually degrading due to the incessant growth in the number of vehicles and the ever-expanding road network, resulting in the increase of road traffic noise. In almost all Indian cities, traffic noise levels exceed the allowable standards as specified by regulatory agencies [5]. Therefore, managing road traffic noise is a challenging task for environmental engineers and urban planners. Urban planners often have to rely on road traffic noise prediction models for their assessment. In India, research studies on road traffic noise pollution are limited [3]. A few important studies were conducted at the Indian Institute of Technology Roorkee [5]. To the best of knowledge of the authors, India does not have an indigenous model that encompasses Indian traffic characteristics and prevailing environmental conditions. At present, the Federal Highway Administration (FHWA) Traffic Noise Model from USA has been widely used in India for traffic noise assessment [5]. But traffic conditions in India are quite different from those in USA. Moreover, differences in the noise emission level of vehicles and noise surveying methods, as well as the mixed traffic and environmental conditions in India, have been found to decrease the prediction accuracy of the FHWA model [1]. Jain et al. [5] have carried out investigations on the development of a comprehensive highway noise prediction model for Indian conditions. However, the deficiency of this model lies in the fact that the correction models used in their study for distance, volume, speed, gradient, ground cover and barrier have been borrowed directly from the FHWA model (USA) and the CoRTN model (UK) [5]. In view of this, there was a need to develop an urban road traffic noise prediction model by taking into consideration the current road traffic conditions in India. Therefore, the main objective of this study is to develop an urban road traffic noise prediction model under uninterrupted traffic flow conditions, taking into account all the major causative factors that influence the outdoor propagation of road traffic noise.

\section{MODEL DEVELOPMENT}

\subsection{Assumptions made for model development}

The following assumptions were made within practical limits without any loss of generality:

1. Vehicles are classified into six categories based on noise emission levels and homogeneity.

2. The road stretch should be straight and level with a reasonably good surface condition and therefore the influence of variation in road interface is neglected.

3. Traffic noise is quantified by the equivalent noise, $L_{\mathrm{eq}}$.

4. All measurements are carried out under normal weather conditions and the effects of wind speed and direction and temperature stratification are neglected.

5. All vehicles moving on roadways in the study locations fulfil the requirements of the Indian Motor Vehicles Act.

6. The background noise in the study locations is limited to $10 \mathrm{~dB}(\mathrm{~A})$.

\subsection{General formula}

The basic methodology followed to develop a noise prediction model for uninterrupted traffic flow conditions is given by:

$$
L_{\mathrm{eq}(1 \mathrm{~h}) i}=L_{0}+\sum L_{i}=L_{0}+\Delta L_{\mathrm{S}}+\Delta L_{\mathrm{Q}}+\Delta L_{\mathrm{D}}+\Delta L_{\mathrm{F}}+\Delta L_{\mathrm{RG}}+\Delta L_{\mathrm{GA}}+\Delta L_{\mathrm{B}},
$$

where $L_{\mathrm{eq}(1 \mathrm{~h}) i}$ is the hourly equivalent noise for the $i$ th class of vehicles; $L_{0}$ is the basic noise prediction model for the $i$ th class of vehicles in $\mathrm{dB}(\mathrm{A}) ; \Delta L_{\mathrm{S}}, \Delta L_{\mathrm{Q}}, \Delta L_{\mathrm{D}}, \Delta L_{\mathrm{F}}, \Delta L_{\mathrm{RG}}, \Delta L_{\mathrm{GA}}$ and $\Delta L_{\mathrm{B}}$ are 
the correction models for traffic speed, traffic volume, distance, finite length of roadway, road gradient, ground absorption and noise barriers in $\mathrm{dB}(\mathrm{A})$, respectively.

\subsection{Reference noise emission level of vehicles}

According to Indian standards, vehicles can be classified into six groups. This classification was made based on noise emission levels of individual vehicles and homogeneity [5].

1. Car/jeep/van

2. Two wheelers (scooter/motorcycle)

3. Light commercial vehicles (LCV)/minibus (MB)

4. Autorickshaw

5. Bus

6. Trucks.

Following the ISO/R 362 (Methodology for Measurement of Individual Vehicle Noise) [4], the reference mean hourly equivalent noise emission levels for six types of vehicles were measured according to the schema in Fig. 1. The free flow of traffic noise was recorded in real road running situations when a vehicle passes the sound level meters kept on both sides of the roadway. The microphone positions are $7.5 \mathrm{~m}$ from the vehicle path and at a height $1.2 \mathrm{~m}$ above the local ground level. The noise emission levels are measured at a reference speed of $50 \mathrm{~km} / \mathrm{h}$. The noise sampling survey was carried out for day noise between 6.00 a.m. and 9.00 p.m. during weekdays at all the study locations. The study was conducted during the period September 2004 to March 2006. The measurement results from 2249 data sets, which were collected from approximately 375 vehicles/type, are given in Table 1.

In mixed traffic, each vehicle has different noise generation characteristics compared with other vehicles which makes the road traffic noise problem a little complex. In order to understand the behaviour of road traffic noise, or to understand the various relationships, it is necessary to convert all vehicles into some equivalence based on their noise generation characteristics. The acoustic equivalence $(E)$ of a particular vehicle represents how much noisier the vehicle is than the reference vehicle. In this study, car/jeep/van was used as the reference. An acoustic equivalence value was

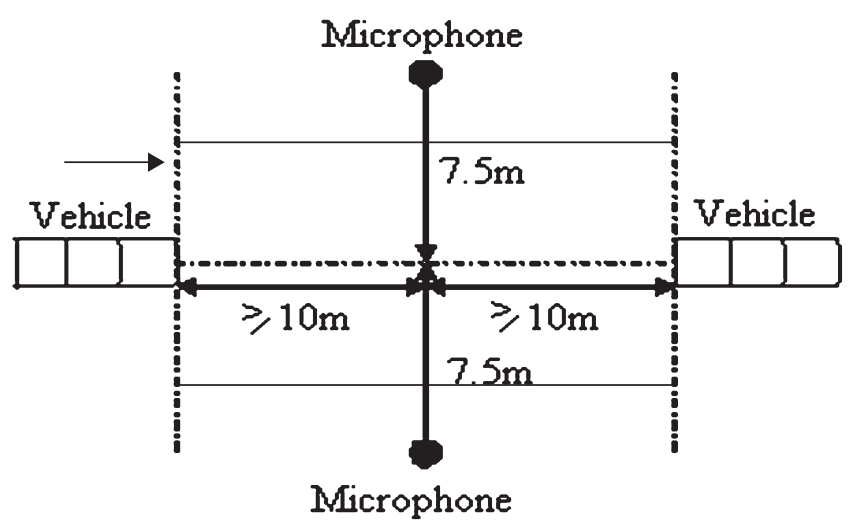

Figure 1: ISO/R 362 vehicle noise measurement procedure. 
Table 1: Reference equivalent noise emission levels for the six classes of vehicles.

\begin{tabular}{lcccccccc}
\hline Vehicle & & & \multicolumn{2}{c}{ Speed $(\mathrm{km} / \mathrm{h})$} & & \multicolumn{3}{c}{$L_{\text {eq(1 })}(\mathrm{dB}(\mathrm{A}))$} \\
\cline { 7 - 8 } \cline { 7 - 9 } Type & Number & & Max. & Min. & & Max. & Min. & Mean \\
\hline Car/jeep/van & 423 & & 87.34 & 31.24 & & 78.34 & 56.62 & 71.40 \\
Two wheelers & 550 & & 93.12 & 26.75 & & 86.73 & 62.54 & 73.12 \\
LCV/minibus & 301 & & 86.42 & 19.62 & & 88.22 & 64.13 & 75.20 \\
Autorickshaw & 327 & & 65.45 & 16.51 & & 91.72 & 61.34 & 78.82 \\
Bus & 451 & & 72.54 & 21.33 & & 95.57 & 65.35 & 80.32 \\
Trucks & 197 & & 65.23 & 19.14 & & 96.44 & 66.72 & 81.24 \\
\hline
\end{tabular}

used to quantify the noise produced by different types of vehicles into a common unit. A composite relationship is then developed based on the factor of acoustic equivalence between the different vehicle classes as indicated below:

$$
\begin{gathered}
E_{\text {Tru }}=10^{(81.24-71.40) / 10}=9.63, \\
E_{\text {Bus }}=10^{(80.32-71.40) / 10}=7.80, \\
E_{\text {Auto }}=10^{(78.82-71.40) / 10}=5.60, \\
E_{\mathrm{LCV} / \mathrm{MB}}=10^{(75.20-71.40) / 10}=2.39, \\
E_{\mathrm{TW}}=10^{(73.12-71.40) / 10}=1.48,
\end{gathered}
$$

where $E_{\text {Tru }}$ indicates that the noise level produced by one truck is equivalent to the noise emitted by $9.63 \mathrm{car} / \mathrm{jeep} / \mathrm{van}$. Similarly, $E_{\mathrm{Bus}}, E_{\mathrm{Auto}}, E_{\mathrm{LCV} / \mathrm{MB}}$ and $E_{\mathrm{TW}}$ indicate that the noise emitted by one bus, autorickshaw, LCV/MB and two wheeler is equivalent to the noise emitted by 7.80, 5.60, 2.39 and $1.48 \mathrm{car} / \mathrm{jeep} / \mathrm{van}$, respectively.

The total equivalent road traffic volume is then calculated by:

$$
\begin{aligned}
Q_{\mathrm{E}} & =Q_{\mathrm{Car} / \mathrm{Jeep} / \mathrm{Van}}+E_{\mathrm{Tru}} Q_{\mathrm{Tru}}+E_{\mathrm{Bus}} Q_{\mathrm{Bus}}+E_{\mathrm{Auto}} Q_{\text {Auto }}+E_{\mathrm{LCV} / \mathrm{MB}} Q_{\mathrm{LCV} / \mathrm{MB}}+E_{\mathrm{TW}} Q_{\mathrm{TW}} \\
& =Q_{\mathrm{Car} / \mathrm{Jeep} / \mathrm{Van}}+9.6 Q_{\mathrm{Tru}}+7.8 Q_{\mathrm{Bus}}+5.6 Q_{\text {Auto }}+2.39 Q_{\mathrm{LCV} / \mathrm{MB}}+1.48 Q_{\mathrm{TW}},
\end{aligned}
$$

where $E_{\mathrm{Tru}}, E_{\mathrm{Bus}}, E_{\mathrm{Auto}}, E_{\mathrm{LCV} / \mathrm{MB}}$ and $E_{\mathrm{TW}}$ are the acoustic equivalence factors for trucks, bus, autorickshaw, LCV/MB and two wheelers, respectively; $Q_{\mathrm{E}}$ is the total hourly equivalent traffic volume in vehicles per hour; $Q_{\mathrm{Car} / J \mathrm{sep} / \mathrm{Van}}, Q_{\mathrm{Tru}}, Q_{\mathrm{Bus}}, Q_{\mathrm{Auto}}, Q_{\mathrm{LCV} / \mathrm{MB}}$ and $Q_{\mathrm{TW}}$ are the hourly traffic volumes for car/jeep/van, trucks, bus, autorickshaw, LCV/MB and two wheelers, respectively.

Similarly, the equivalent traffic speed can be calculated by:

$$
\begin{aligned}
S_{\mathrm{E}}= & \left(9.6 Q_{\mathrm{Tru}} S_{\mathrm{Tru}}+7.8 Q_{\mathrm{Bus}} S_{\text {Bus }}+5.6 Q_{\text {Auto }} S_{\text {Auto }}+2.39 Q_{\mathrm{LCV} / \mathrm{MB}} S_{\mathrm{LCV} / \mathrm{MB}}+1.48 Q_{\mathrm{TW}} S_{\mathrm{TW}}\right. \\
& \left.+Q_{\mathrm{Car} / \mathrm{Jeep} / \mathrm{Van}} S_{\mathrm{Car} / \mathrm{see} / \mathrm{Van}}\right) / Q_{\mathrm{E}},
\end{aligned}
$$

where $S_{\mathrm{E}}$ is the equivalent speed of traffic in $\mathrm{km} / \mathrm{h} ; S_{\mathrm{Car} / \mathrm{Jeep} / \mathrm{Van}}, S_{\mathrm{Tru}}, S_{\mathrm{Bus}}, S_{\mathrm{Auto}}, S_{\mathrm{LCV} / \mathrm{MB}}$ and $S_{\mathrm{TW}}$ are the mean speeds in $\mathrm{km} / \mathrm{h}$ for car/jeep/van, trucks, bus, autorickshaw, LCV/MB and two wheelers, respectively.

2.4 Basic noise prediction model $\left(L_{0}\right)$

The noise emitted by a vehicle over a wide range of speed can be fitted in the following form.

$$
L_{0}=C+K \log S,
$$


Table 2: Basic noise prediction model for each class of vehicles.

\begin{tabular}{lcc}
\hline Vehicle class & Basic noise prediction model & $r^{2}$ value \\
\hline Car/jeep/van & $L_{0}=9.20+33.76 \log S$ & 0.82 \\
Two wheelers & $L_{0}=16.26+32.19 \log S$ & 0.81 \\
LCV/minibus & $L_{0}=21.74+30.12 \log S$ & 0.85 \\
Autorickshaw & $L_{0}=2.34+41.12 \log S$ & 0.84 \\
Bus & $L_{0}=14.60+36.14 \log S$ & 0.82 \\
Trucks & $L_{0}=11.04+38.74 \log S$ & 0.83 \\
\hline
\end{tabular}

where $L_{0}$ is the hourly equivalent noise emission for the $i$ th class of vehicles, $S$ is the vehicle spot speed in $\mathrm{km} / \mathrm{h}(S>0), C$ and $K$ are constants (computed by regression analysis of field data for a given class of vehicle).

The vehicle noise data collected over a wide range of speeds was analyzed using a Microsoft Excel Spreadsheet. Linear regression analysis was carried out to develop a basic noise prediction model for each class of vehicles. The resulting models for each class of vehicles are given in Table 2.

The total noise due to all types/categories of vehicles is then calculated by:

$$
\begin{aligned}
& L_{\mathrm{eqT}}=\sum_{\text {Sum }}^{\mathrm{dB}(\mathrm{A})} L_{\mathrm{eq}}(\mathrm{Car} / \mathrm{Jeep} / \mathrm{Van}+\mathrm{TW}+\mathrm{LCV} / \mathrm{MB}+\mathrm{Bus}+\text { Auto }+ \text { Trucks })
\end{aligned}
$$

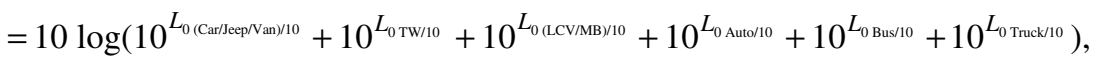

where $L_{\text {eqT }}$ is the total equivalent noise due to all classes of vehicles.

2.5 Correction models for speed $\left(\Delta L_{\mathrm{S}}\right)$, traffic volume $\left(\Delta L_{\mathrm{Q}}\right)$, distance $\left(\Delta L_{\mathrm{D}}\right)$ and finite length of road segment $\left(\Delta L_{\mathrm{F}}\right)$

In the study locations, the average spot speed of traffic was $50 \mathrm{~km} / \mathrm{h}$. Therefore, when traffic speed differs from the $50 \mathrm{~km} / \mathrm{h}$ benchmark, a correction factor should be applied to the reference noise emission level.

The correction factor for traffic speed is given by:

$$
\Delta L_{\mathrm{S}}=A_{1}\left(S_{\mathrm{E}}-50\right)
$$

A correction should also be considered for traffic volume as well:

$$
\Delta L_{\mathrm{Q}}=A_{2} 10 \log Q_{\mathrm{E}}-A_{3} 10 \log S_{\mathrm{E}} .
$$

In open areas, the measured traffic noise levels in the study area are also influenced by the distance between the source and the reception point. Therefore, it is necessary to apply a necessary correction to the measured noise levels for distances greater than the reference distance $\left(D_{0}\right)$ of $7.5 \mathrm{~m}$ from the centre line of the roadway. This correction is often referred to as the distance correction.

The distance correction can be calculated by:

$$
\Delta L_{\mathrm{D}}=A_{4} 10 \log \left(D_{0} / D\right)
$$

where $D$ is the equivalent distance from the road segment to the reception point, $m$. 


$$
D=\sqrt{D_{\mathrm{N}} \times D_{\mathrm{F}}},
$$

where $D_{\mathrm{N}}$ and $D_{\mathrm{F}}$ are the perpendicular distances from the receiver to the centre line of the nearest and far lanes in $m$, respectively.

The correction for the finite length of the road segment is determined by the angle subtended by the road segment relative to the receiver $(\Delta \phi)$ and is given by:

$$
\Delta L_{\mathrm{F}}=10 \log \left(\Delta \phi / 180^{\circ}\right) .
$$

The hourly equivalent traffic noise can now be expressed for any point from a flat road segment without shielding effects and ground absorption in the form:

$$
L_{\mathrm{eq}(1 \mathrm{~h})}=A_{0}+A_{1}\left(S_{\mathrm{E}}-50\right)+A_{2} 10 \log Q_{\mathrm{E}}-A_{3} 10 \log S_{\mathrm{E}}+A_{4} 10 \log \left(D_{0} / D\right)+\Delta L_{\mathrm{F}}
$$

To determine the coefficients $A_{0}, A_{1}, A_{2}, A_{3}$ and $A_{4}$, traffic data were collected from 34 uninterrupted traffic flow locations in the metropolitan city of Bangalore in Karnataka, India. These locations encompass most urban roads and two main highways with different traffic flows and speeds. The traffic volume in the study locations varied between 3000 and 10,000 vehicles per hour and traffic speed ranged between 25 and $90 \mathrm{~km} / \mathrm{h}$. The resulting equation for hourly equivalent traffic noise is given by:

$$
\begin{aligned}
L_{\mathrm{eq}(1 \mathrm{~h})}= & 58.12+0.39\left(S_{\mathrm{E}}-50\right)+7.84 \log Q_{\mathrm{E}}-9.21 \log S_{\mathrm{E}}+13.54 \log \left(D_{0} / D\right) \\
& +10 \log \left(\Delta \phi / 180^{\circ}\right),
\end{aligned}
$$

coefficient of determination $\left(r^{2}\right)=0.82$; standard error $(\mathrm{SE})=2.32 \mathrm{~dB}(\mathrm{~A})$; number of data $=321$.

\subsection{Correction model for ground absorption $\left(\Delta L_{\mathrm{GA}}\right)$}

If the ground surface between the edge of the near side carriageway of the road segment and the reception point is totally or even partially absorbent in nature (e.g. grass land, cultivated fields or plantations), an additional correction for ground cover, often referred to as ground absorption correction, must be taken into account [4]. Field measurements were taken from 17 locations with soft ground cover $(P)$ of $25 \%, 50 \%$ and $75 \%$. The locations chosen were backyards with gardens, paddy fields, tree density on either side of the roads and mixture of absorbent (grass cover) and non-absorbent areas. The site locations are classified into hard or soft based on the criteria given in the FHWA table [5]. All measurements were carried out under normal weather conditions and the effects of wind speed and direction and temperature stratification are neglected.

The attenuation values of traffic noise due to ground absorption was estimated from the difference between the calculated noise levels and measured noise levels when soft ground cover was equal to $25 \%, 50 \%$ and $75 \%$. The geometrics of calculating the correction for ground absorption is shown in Fig. 2. The ground absorption is progressive with distance [4]. Therefore, field measurements were taken at receiver heights of $1.2,3,5,7,10,15$ and $18 \mathrm{~m}$, and horizontal distances of 10, 15, $20,30,40,50$ and $60 \mathrm{~m}$ from centre line of the roadway. However, it remains intact when, $H_{\mathrm{r}}$ (receiver height), reaches $15 \mathrm{~m}$.

The basic concept followed to develop the ground absorption correction model is given by:

$$
L_{\mathrm{GA}}=a 10 \log \left(D_{0} / D\right) \text {, }
$$

where $\alpha$ is a site parameter whose value depends on site conditions. 


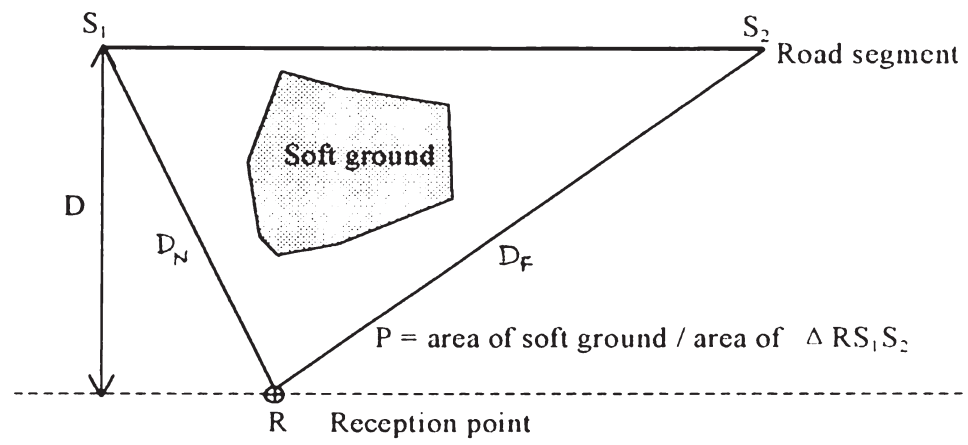

Figure 2: Geometrics of calculating the correction for ground absorption.

Based on analysis of field data, an equation was developed for the site parameter $(\alpha)$. The resulting equation is given by:

$$
a= \begin{cases}1.0 \times(1+P / 100) & \text { if } H_{\mathrm{r}} \leq 3 \mathrm{~m}, \\ 1.2 \times(1+P / 100) \times\left(1-H_{\mathrm{r}} / 15\right) & \text { if } 3 \mathrm{~m}<H_{\mathrm{r}}<15 \mathrm{~m}, \\ 0 & \text { otherwise }\end{cases}
$$

where $P$ is the percentage of soft ground cover.

\subsection{Correction model for road gradient $\left(\Delta L_{\mathrm{RG}}\right)$}

The noise emitted by traffic flow is also influenced by the gradient of the road segment. Generally, road gradient causes an increase in traffic noise for upward flows and a decrease in noise for downhill flows [4]. Therefore, an adjustment factor should be introduced to predicted noise levels whenever a gradient exists. Field measurements were taken at 14 locations having different road gradients ranging from $1.5 \%$ to $10.5 \%$.

The basic concept used to develop the gradient correction model is given by:

$$
\Delta L_{\mathrm{RG}}= \pm \frac{\left(C_{1} Q_{\text {Truck }}+C_{2} Q_{\mathrm{Bus}}+C_{3} Q_{\mathrm{LCV} / \mathrm{MB}}+C_{4} Q_{\text {Auto }}+C_{5} Q_{\mathrm{TW}}+C_{6} Q_{\mathrm{Car} / \mathrm{Jeep} / \mathrm{Van}}\right) \times G}{\left(Q_{\text {Truck }}+Q_{\mathrm{Bus}}+Q_{\mathrm{LCV} / \mathrm{MB}}+Q_{\text {Auto }}+Q_{\mathrm{TW}}+Q_{\mathrm{Car} / \mathrm{Jeep} / \mathrm{Van}}\right)},
$$

where $G=$ road gradient $(\%)$.

Based on the observed field data at study locations and considering the roadway gradient $(G)$ in percentage, the necessary traffic noise adjustments for highway segments with gradient takes the following form.

For uphill flow,

$$
\Delta L_{\mathrm{UG}}=\frac{\left(0.72 Q_{\mathrm{Truck}}+0.63 Q_{\mathrm{Bus}}+0.45 Q_{\mathrm{LCV} / \mathrm{MB}}+0.42 Q_{\mathrm{Auto}}+0.40 Q_{\mathrm{TW}}+0.38 Q_{\mathrm{Car} / \mathrm{Jeep} / \mathrm{Van}}\right) \times G}{\left(Q_{\text {Truck }}+Q_{\mathrm{Bus}}+Q_{\mathrm{LCV} / \mathrm{MB}}+Q_{\mathrm{Auto}}+Q_{\mathrm{TW}}+Q_{\mathrm{Car} / \mathrm{Jeep} / \mathrm{Van}}\right)} .
$$


For downhill flow,

$$
\Delta L_{\mathrm{DG}}=-\frac{\left(0.65 Q_{\text {Truck }}+0.53 Q_{\mathrm{Bus}}+0.40 Q_{\mathrm{LCV} / \mathrm{MB}}+0.38 Q_{\text {Auto }}+0.36 Q_{\mathrm{TW}}+0.32 Q_{\mathrm{Car} / \mathrm{Jeep} / \mathrm{Van}}\right) \times G}{\left(Q_{\text {Truck }}+Q_{\mathrm{Bus}}+Q_{\mathrm{LCV} / \mathrm{MB}}+Q_{\text {Auto }}+Q_{\mathrm{TW}}+Q_{\mathrm{Car} / \mathrm{Jee} / \mathrm{Van}}\right)} .
$$

In the above equations, $\Delta L_{\mathrm{UG}}$ is the correction model for up gradient in $\mathrm{dB}(\mathrm{A})$ and $\Delta L_{\mathrm{DG}}$ is the correction model for down gradient in $\mathrm{dB}(\mathrm{A})$.

\subsection{Correction model for noise barriers $\left(\Delta L_{\mathrm{B}}\right)$}

Attenuation of noise due to barrier shielding is an important mechanism by which road traffic noise levels are lowered [5]. The shielding can be provided by different types of noise barriers such as berms, walls and large buildings. Barriers affect sound propagation by interrupting the sound waves and creating an acoustic shadow zone. In this study, reductions in traffic noise at existing barriers were observed only at three locations. Therefore, sufficient field data were not available to develop the correction model for noise barriers. Hence, the barrier correction model from the FHWA model [1] was used.

The FHWA model for barrier correction is given by:

$$
\Delta L_{\mathrm{B}}=10 \log \left[\frac{1}{\phi_{\mathrm{R}}-\phi_{\mathrm{L}}} \int_{\varphi_{\mathrm{L}}}^{\phi_{\mathrm{R}}} 10^{-\Delta i / 10} \mathrm{~d} \phi\right],
$$

where $\Delta L_{\mathrm{B}}$ is the attenuation for the $i$ th class of vehicles and $\phi_{\mathrm{R}}$ and $\phi_{\mathrm{L}}$ are the angles measured from the perpendicular to the right and left ends of the barriers, respectively.

2.9 Final form of traffic noise prediction model for uninterrupted traffic flow

By incorporating all the correction models given above, it is possible to predict the equivalent sound level produced by road traffic at any reception point. The traffic noise prediction model for uninterrupted traffic flow conditions has the following final form:

$$
\begin{aligned}
L_{\mathrm{eq}(1 \mathrm{~h})}= & 58.12 & & \\
& +0.39\left(S_{\mathrm{E}}-50\right)-9.21 \log S_{\mathrm{E}} & & \text { Correction for traffic speed } \\
& +7.84 \log Q_{\mathrm{E}} & & \text { Correction for traffic volume } \\
& +13.54 \log \left(D_{0} / D\right) & & \text { Correction for distance } \\
& +a 10 \log \left(D_{0} / D\right) & & \text { Correction for ground absorption } \\
& +10 \log \left(\Delta \phi / 180^{\circ}\right) & & \text { Correction for finite length of road segment } \\
& +\Delta L_{\mathrm{RG}} & & \text { Correction for road gradient } \\
& +\Delta L_{\mathrm{B}} & & \text { Correction for noise barriers. }
\end{aligned}
$$

\section{MODEL VALIDATION}

In order to validate the model, another set of field data were collected from five uninterrupted traffic flow locations in Mysore city in Karnataka, India. The details of the study locations chosen are given in Table 3, and the observed field data from these five locations are given in Table 4 and Table 5.

Sample calculation for prediction of traffic noise levels for location 1 using the validation data set is done as follows. 
Table 3: Locations chosen for model validation in Mysore city.

\begin{tabular}{|c|c|c|c|c|c|}
\hline $\begin{array}{l}\text { Location } \\
\text { number }\end{array}$ & Location details & $\begin{array}{l}\text { Road } \\
\text { gradient }\end{array}$ & Site condition & $\begin{array}{l}\text { Noise } \\
\text { barrier }\end{array}$ & Remarks \\
\hline 1 & $\begin{array}{l}\text { Bangalore-Mysore road } \\
\text { near Siddalingpura }\end{array}$ & $4 \% \mathrm{UG}$ & Soft $\left(P=20 \% ; \Delta \phi=160^{\circ}\right)$ & No & \\
\hline 2 & $\begin{array}{l}\text { Brindavan Extension } \\
\text { towards KRS }\end{array}$ & $3 \% \mathrm{UG}$ & $\operatorname{Hard}\left(\Delta \phi=155^{\circ}\right)$ & No & \\
\hline 3 & $\begin{array}{l}\text { Basappa Memorial } \\
\text { Hospital }\end{array}$ & - & $\operatorname{Hard}\left(\Delta \phi=145^{\circ}\right)$ & No & $H_{\mathrm{eff}}<3 \mathrm{~m}$ \\
\hline 4 & $\begin{array}{l}\text { Ashokapura near Mysore } \\
\text { factory }\end{array}$ & - & $\operatorname{Hard}\left(\Delta \phi=140^{\circ}\right)$ & No & \\
\hline 5 & Race Club Road & - & $\operatorname{Hard}\left(\Delta \phi=160^{\circ}\right)$ & No & \\
\hline
\end{tabular}

Table 4: Summary of field traffic data collected at study locations in Mysore city.

\begin{tabular}{|c|c|c|c|c|c|c|c|c|c|}
\hline \multirow[b]{2}{*}{$\begin{array}{l}\text { Study } \\
\text { location } \\
\text { no. }\end{array}$} & \multirow[b]{2}{*}{$L_{\mathrm{eq}} \mathrm{dB}(\mathrm{A})$} & \multirow[b]{2}{*}{ Dist. $(D)$} & \multirow[b]{2}{*}{$\begin{array}{c}\text { Overall } \\
\text { mean speed } \\
(\mathrm{km} / \mathrm{h})\end{array}$} & \multicolumn{6}{|c|}{ Traffic Volume (vehicles/h) } \\
\hline & & & & TW & $\begin{array}{l}\text { Car/ } \\
\text { jeep/ } \\
\text { van }\end{array}$ & Auto & $\mathrm{LCV} / \mathrm{MB}$ & Bus & Trucks \\
\hline 1 & 78.21 & 7.8 & 68.42 & 77 & 146 & 12 & 85 & 122 & 35 \\
\hline 2 & 75.40 & 7.5 & 76.81 & 88 & 76 & 18 & 43 & 34 & 21 \\
\hline 3 & 76.42 & 8.1 & 65.12 & 146 & 65 & 88 & 64 & 56 & 7 \\
\hline 4 & 77.03 & 7.9 & 71.81 & 97 & 42 & 36 & 36 & 28 & 11 \\
\hline 5 & 75.12 & 7.6 & 67.20 & 153 & 67 & 53 & 34 & 42 & 5 \\
\hline
\end{tabular}

Table 5: Observed mean spot speed of vehicles at study locations in Mysore city.

\begin{tabular}{lc}
\hline & Mean spot speed $(\mathrm{km} / \mathrm{h})$ \\
\hline Two wheelers & 76.56 \\
Car/jeep/van & 75.34 \\
Autorickshaw & 56.42 \\
LCV/minibus & 71.23 \\
Bus & 68.82 \\
Trucks & 63.61 \\
\hline
\end{tabular}

3.1 Estimation of model parameters

The estimation of model parameters for uninterrupted traffic flow at location 1 can be calculated as follows.

Equivalent traffic flow $\left(Q_{\mathrm{E}}\right)$ :

$$
\begin{aligned}
Q_{\mathrm{E}} & =Q_{\mathrm{Car} / \mathrm{Jeep} / \mathrm{Van}}+9.6 Q_{\mathrm{Tru}}+7.8 Q_{\mathrm{Bus}}+5.6 Q_{\text {Auto }}+2.39 Q_{\mathrm{LCV} / \mathrm{Minibus}}+1.48 Q_{\mathrm{TW}} \\
& =146+9.6(35)+7.8(122)+5.6(12)+2.39(85)+1.48(77) \\
& =1817.91 \text { vehicles } / \mathrm{h} .
\end{aligned}
$$


Equivalent traffic speed $\left(S_{\mathrm{E}}\right)$ :

$$
\begin{aligned}
S_{\mathrm{E}}= & \left(9.6 Q_{\mathrm{Tru}} S_{\mathrm{Tru}}+7.8 Q_{\mathrm{Bus}} S_{\mathrm{Bus}}+5.6 Q_{\text {Auto }} S_{\text {Auto }}+2.39 Q_{\mathrm{LCV} / \mathrm{MB}} S_{\mathrm{LCV} / \mathrm{MB}}+1.48 Q_{\mathrm{TW}} S_{\mathrm{TW}}\right. \\
& +Q_{\mathrm{Car} / \mathrm{Jeep} / \mathrm{Van}} S_{\mathrm{Car} / \mathrm{Jeep} / \mathrm{Van}} / Q_{\mathrm{E}} \\
= & (9.6(35)(63.61)+7.8(122)(68.82)+5.6(12)(56.42)+2.39(85)(71.23) \\
& +1.48(77)(76.56)+146(75.34)) /(1817.91) \\
= & 68.77 \mathrm{~km} / \mathrm{h} .
\end{aligned}
$$

Distance correction model:

$$
\Delta L_{\mathrm{D}}=13.54 \log \left(D_{0} / D\right) .
$$

From Table 4, $D=7.8 \mathrm{~m}$ and $D_{0}=7.5 \mathrm{~m}$ (reference distance),

$$
\Delta L_{\mathrm{D}}=13.54 \log (7.5 / 7.8)=-0.17 \mathrm{~dB}(\mathrm{~A}) .
$$

Ground absorption model:

$$
L_{\mathrm{GA}}=\alpha 10 \log \left(D_{0} / D\right)
$$

where, $\alpha=1.0(1+P / 100)$ and $P=20 \% ; \alpha=1.0(1+20 / 100)=1.2$,

$$
\Delta L_{\mathrm{GA}}=1.2 \times 10 \log (7.5 / 7.8)=-0.2 \mathrm{~dB}(\mathrm{~A}) .
$$

Correction model for finite length of road segment:

$$
\Delta L_{\mathrm{F}}=10 \log \left(\Delta \phi / 180^{\circ}\right) .
$$

From Table $4, \Delta \phi=160^{\circ}$,

$$
\Delta L_{\mathrm{F}}=10 \log \left(160^{\circ} / 180^{\circ}\right)=-0.51 \mathrm{~dB}(\mathrm{~A}) .
$$

Road gradient correction model:

$$
\begin{aligned}
\Delta L_{\mathrm{UG}} & =\frac{\left(0.72 Q_{\text {Truck }}+0.63 Q_{\mathrm{Bus}}+0.45 Q_{\mathrm{LCV} / \mathrm{MB}}+0.42 Q_{\text {Auto }}+0.40 Q_{\mathrm{TW}}+0.38 Q_{\mathrm{Car} / \mathrm{Jeep} / \mathrm{Van}}\right) \times G}{\left(Q_{\text {Truck }}+Q_{\mathrm{Bus}}+Q_{\mathrm{LCV} / \mathrm{MB}}+Q_{\text {Auto }}+Q_{\mathrm{TW}}+Q_{\mathrm{Car} / \mathrm{Jee} / \mathrm{Van}}\right)} \\
& =\frac{[0.72(35)+0.63(122)+0.45(85)+0.42(12)+0.40(77)+0.38(146)] \times 4}{(35+122+85+12+77+146)} \\
& =1.94 \mathrm{~dB}(\mathrm{~A}) .
\end{aligned}
$$

By substituting all parameter values into the final form of the traffic noise prediction model as given in eqn (11), the predicted result of the model at location 1 is given by:

$$
\begin{aligned}
L_{\mathrm{eq}(1 \mathrm{~h})}= & 58.12+0.39\left(S_{\mathrm{E}}-50\right)-9.21 \log S_{\mathrm{E}}+7.84 \log Q_{\mathrm{E}}+\Delta L_{\mathrm{D}}+\Delta L_{\mathrm{F}}+\Delta L_{\mathrm{RG}}+\Delta L_{\mathrm{GA}} \\
= & 58.12+0.39(68.77-50)-9.21 \log (68.77)+7.84 \log (1817.91)-0.17-0.20 \\
& -0.51+1.94 \\
= & 75.14 \mathrm{~dB}(\mathrm{~A})
\end{aligned}
$$

From Table 4, the observed field value at location 1 is $78.21 \mathrm{~dB}(\mathrm{~A})$. Hence, a difference of $3.07 \mathrm{~dB}(\mathrm{~A})$ was observed between the field and predicted values of traffic noise at location 1. Similar calculations were also done for other locations and the results are shown in Table 6. 
Table 6: Field observed and predicted noise levels at study locations in Mysore city.

\begin{tabular}{lccc}
\hline Study location no. & $L_{\mathrm{eq}}, \mathrm{dB}(\mathrm{A})$ (predicted) & $L_{\mathrm{eq}}, \mathrm{dB}(\mathrm{A})$ (observed) & Difference, $\mathrm{dB}(\mathrm{A})$ \\
\hline 1 & 75.14 & 78.21 & 3.07 \\
2 & 72.13 & 75.40 & 3.27 \\
3 & 74.02 & 76.42 & 2.4 \\
4 & 75.30 & 77.03 & 1.73 \\
5 & 72.64 & 75.12 & 2.48 \\
\hline
\end{tabular}

Table 7: Paired $t$-test at 5\% level of significance for field data collected from Mysore city.

\begin{tabular}{|c|c|c|}
\hline Particulars & $L_{\mathrm{eq}}, \mathrm{dB}(\mathrm{A})$ (predicted) & $L_{\mathrm{eq}}, \mathrm{dB}(\mathrm{A})$ (observed) \\
\hline$\overline{\text { Mean }}$ & 73.82 & 76.43 \\
\hline Variance & 2.20 & 1.59 \\
\hline Observations & 5 & 5 \\
\hline Co-efficient of determination & \multicolumn{2}{|c|}{0.78} \\
\hline Degrees of freedom & \multicolumn{2}{|c|}{4} \\
\hline Hypothesized mean difference & \multicolumn{2}{|c|}{0} \\
\hline$t$-statistic & \multicolumn{2}{|c|}{1.11} \\
\hline$t$-critical & \multicolumn{2}{|c|}{1.6509} \\
\hline
\end{tabular}

Testing of the goodness of fit of the model was also done using the paired $t$-test technique. The paired $t$-test results of the model at $5 \%$ level of significance with data from five locations in Mysore city are shown in Table 7. The testing results show that for four degrees of freedom and 5\% level of significance, the model gave a $t$-statistical value which was less than the $t$-critical value (from the $t$-table). This means that each set of observed and predicted values for the locations can be rated as 'good', which means that observed and predicted noise levels do not vary considerably at $5 \%$ level of significance. On other hand, a 'poor' rating indicates that the observed and predicted noise levels vary considerably at $5 \%$ level of significance. The mean difference between observed and predicted values is $2.6 \mathrm{~dB}(\mathrm{~A})$ with $r^{2}$ value of 0.78 . The corresponding variance for observed and predicted values was found to be 2.20 and $1.59 \mathrm{~dB}(\mathrm{~A})$, respectively. These statistical results illustrate how well the predicted values can be fitted to the observed ones.

\section{COMPARISON OF MODEL WITH FHWA MODEL}

In order to establish the performance of the developed model, the prediction results were compared with those obtained from the FHWA model (USA). Comparative statistical tests were applied to the results of both models using the paired $t$-test technique. The null hypothesis was applied using paired $t$-test which stated that the mean value of difference between pairs of measured traffic noise level values and predicted ones is equal to zero. The paired $t$-test results of the models at $5 \%$ level of significance are given in Table 8. From this table, it can be observed that the $t$-statistical value for the model developed in this study is less than its $t$-critical value. This means that the predicted values from the present model are in good agreement with the field observed values than the FHWA model. This is due to the differences in the noise emission level of vehicles, noise surveying methods, topography and environmental conditions prevailing on roadways in USA. 
Table 8: Comparative paired $t$-test results at $5 \%$ level of significance.

\begin{tabular}{lccc}
\hline Model used & Sample $(N)$ & $t$-statistic & $t$-critical \\
\hline FHWA model & 77 & 2.12 & 1.6509 \\
Regression model of the present study & 77 & 1.32 & 1.6509 \\
\hline
\end{tabular}

\section{CONCLUSIONS}

Based on this study, it can be concluded that the developed model can be used by urban planners and environmental engineers to improve the efficiency of urban noise management in the Indian context. The model is accurate to $2.6 \mathrm{~dB}(\mathrm{~A})$ for a validation data set with $r^{2}$ value of 0.78 . The results of model comparison show that the predicted values from the present model are in good agreement with the field observed values than the FHWA model, which is generally used in India. This is mainly due to differences in the noise emission level of vehicles, traffic flow patterns, noise surveying methods, topography and environmental conditions prevailing on roadways in USA. However, there is a need to refine the model further by considering the effect of air absorption, noise barriers, wind speed and direction, and temperature stratification.

\section{ACKNOWLEDGEMENTS}

The first author gratefully acknowledges the financial assistance provided by the All India Council for Technical Education, New Delhi, under the scheme 'Career Award for Young Teachers' and the authorities of Adhiyamaan College of Engineering, Hosur, Tamil Nadu, and P.E.S. College of Engineering, Mandya, Karnataka, for providing necessary facilities and support.

\section{REFERENCES}

[1] Nirjar, R.S., Jain, S.S., Parida, M. \& Katiyar, V.S., Study of transport related noise pollution in Delhi. J. Institution of Engineers (1)-Env., 84, pp. 6-15, 2003.

[2] Johnson, D.R. \& Saunders, E.G., The evaluation of noise from freely flowing road traffic. Journal of Sound and Vibration, 7(2), pp. 287-309, 1968.

[3] Kudesia, V.P. \& Tiwari, T.N., Noise Pollution and Its Control, Pragati Prakashan: Meerut, India, 2000.

[4] Li, B., Tao, S., Dawson, R.W., Cao, J. \& Lam, K., A GIS based road traffic noise prediction model. Applied Acoustics, 63(6), pp. 679-691, 2002.

[5] Jain, S.S., Parida, M. \& Bhattacharya, C.C., Development of comprehensive highway noise model for Indian conditions. J. Indian Road Congress, 62(3), pp. 453-488, 2000.

[6] Roswell, A.H., Louis, F.C. \& James, H.G., Comprehensive software library for highway noise analysis. J. Computing in Civil Engineering, 9(2), paper no. 6898, 1995. 